\title{
Author Correction: Epidemic T2DM, early development and epigenetics: implications of the Chinese Famine
}

\author{
Paul Zimmet (D), Zumin Shi(D, Assam El-Osta and Linong Ji
}

Nature Reviews Endocrinology (2018) https://doi.org/10.1038/s41574-018-0106-1

Published online 11 October 2018

In the version of this article published online and in print, there was a mistake in the legend of Fig. 2 regarding the descriptions of the red and blue colours in the Figure. The text should have read 'The blue and red colours represent regions (provinces) with wheat and rice as the staple food, respectively.' This has now been corrected in the HTML and PDF version of the article.

https://doi.org/10.1038/s41574-019-0199-1 I Published online 1 April 2019 